\title{
Excitation Functions for the Proton Irradiation on ${ }^{45} \mathrm{Sc}$ Target
}

\author{
Susan Shukur NOORI ${ }^{1 *}$, İskender AKKURT ${ }^{2}$, Nurdan KARPUZ DEMIR ${ }^{3}$ \\ ${ }^{1}$ Kirkuk University, College of Science, Kirkuk, IRAQ \\ ${ }^{2}$ Süleyman Demirel University, Sciences \& Arts Faculty, Isparta, TURKEY \\ ${ }^{3}$ Amasya University, Sabuncuoğlu Şerefeddin Vocational School of Health Services, Amasya, TURKEY \\ * Corresponding Author : susannoori@uokirkuk.edu.iq \\ ORCID: 0000-0003-2134-6337
}

\section{Article Info:}

DOI: $10.22399 /$ ijcesen.547000

Received : 30 March 2019

Accepted : 13 July 2019

\section{$\underline{\text { Keywords }}$}

Excitation functions

Proton irradiation

TALYS 1.6 nuclear reaction

simulation code

\begin{abstract}
:
In the nuclear medicine for the positron emission tomography, the injected positron emitter leads to two $511 \mathrm{keV} \gamma$-rays. One of the most promising radionuclides is ${ }^{45} \mathrm{Sc}$. In this study, the main purpose was to investigate the excitation functions for the reactions ${ }^{45} \mathrm{Sc}(\mathrm{p}, \mathrm{x})$. TALYS 1.6 nuclear reaction simulation code was used for the excitation functions. These calculated excitation functions have been discussed and compared with each other and with Experimental Nuclear Reaction Data Library (EXFOR).
\end{abstract}

\section{Introduction}

Production cross sections for charged particle especially protons induced of nuclear reactions on metals are important for development of improved nuclear reaction theory and have a big role in many applications practical (nuclear wear measurement, medical radioisotope production, radiobiology etc.). All over the world the cyclotrons and accelerators number are continuous increasing to production of radioisotopes for both diagnostic and therapeutic purposes because medical applications of nuclear radiations are of considerable interest for the humankind nowadays [1].

Variations of cross sections represented by the excitation functions with incident energy for appointed reactions used in field of radioisotope production for example for a particular reaction type determine required particle energies and optimal energy ranges calculate the radioisotope production yield which can be expected and calculate the production yields for radionuclides impurities, for determine the need for isotopically enriched target materials especially for medical radioisotope production [2]. The present study was carried out using a Monte Carlo nuclear reaction simulation code TALYS 1.6, For some interactions of proton with Scandium -45. Using Monte Carlo methods other several work have been done in this field [3-8].

\section{Materials and Method}

Theoretically and by used the model calculations TALYS 1.6 code, the production cross-sections of the residual radionuclides are obtained from the ${ }^{45} \mathrm{Sc}(\mathrm{p}, \mathrm{x})$ processes with proton energies up to 100 $\mathrm{MeV}$, these calculation for nuclear reaction crosssections, are usually employed in cases where there is a shortage of experimental data or there are other controversies. Moreover, it ensure the internal consistency of the data, and also allows us to predict and extrapolate the experimental data. TALYS is a computer code system for the simulation, analysis and prediction of nuclear reactions. The basic objective behind its construction is the simulation of nuclear reactions that involve neutrons, photons, protons, deuterons, tritons, ${ }^{3} \mathrm{He}$-and alpha particles. TALYS integrates the optical model, direct, preequilibrium, fission and statistical nuclear reaction models in one calculation scheme and gives a prediction for all the open reaction channels [9]. In using a Monte Carlo method for nuclear data evaluation a series of 
correlations can be extracted from the previous results. At this point, it is worth mentioning that for each calculated quantity, thousands of values are obtained. These quantities can be differential nuclear data such as total and partial cross sections, isomer and residual production cross sections, continuum and discrete c-ray production cross sections, angular distributions, energy spectra, angular distributions, recoil cross sections, as well as double differential spectra. To achieve this, a suite of nuclear reaction models has been implemented into a single code system $[10,11]$.

\section{Results and discussion}

${ }^{45} \mathrm{Ti}$ with a half-life of $3.08 \mathrm{~h}$ is a positron-emitting radioisotope with a positron branching of $85 \%$ and a decay of $15 \%$ by electron capture with $\mathrm{E}(\beta+$ $\max )$, i. e., $1.04 \mathrm{MeV}$ de cays to ${ }^{45} \mathrm{Sc}$ [12]. ${ }^{44} \mathrm{Sc} 3.97 \mathrm{~h}$ half-life is one of radioisotope used in positron emission tomography (PET) application for studying bone disease. ${ }^{44} \mathrm{Sc}$ is a positron emitter with $\beta+$ branching $94.3 \%$. K Potassium having a half-life of 12.36 hours; is used as a radioactive tracer in studies of potassium distribution in bodily fluids, and in localization of brain tumors. And ${ }^{44} \mathrm{Ti}$ with half-life of 60 years were obtained via the Sc $(\mathrm{p}, 2 \mathrm{n})$ nuclear reaction [13, 14]. These isotopes were obtained in our study by interaction of proton with ${ }^{45} \mathrm{Sc}$.

Early in the development of nuclear medicine, the biological significance of these radioisotopes was realized, and positron emitters were viewed with great promise. The availability of these biological radioisotopes has made a major impact on PET research. A vast array of biological radiotracers has been used to help understand kinetics and function. In $\beta+$ decay process, proton transformed to neutron in the nucleus with emission a $\beta+$ particle and a neutrino after few millimeters in the tissue facing with antiparticle. When that happens, the electron positron pair is annihilated each other and transformed into two opposite direction photons with energy $0.511 \mathrm{MeV}$. These photons can be detected by the coincidence technique used in (PET). In nuclear medicine (PET) Technique is important in the diagnosis treatment planning, and evaluation of the treatment response in cancer patients $[15,16]$. Production cross sections of proton induced nuclear reactions are important for many medical applications and for development of nuclear reaction theory [17]. In this study the production cross-sections are shown in Figures 1- 5 together with the available literature data and the evaluated data using Monte Carlo code TALYS 1.6 which is the nuclear reaction simulation code. The results are compared with the experimental data existing in the EXFOR [18]. In this study we have investigated only those reactions which produced ${ }^{45} \mathrm{Sc}(\mathrm{p}, \mathrm{n}){ }^{45} \mathrm{Ti}(\mathrm{Q}=-2.84441 \mathrm{MeV}),{ }^{45} \mathrm{Sc}(\mathrm{p}, 2 \mathrm{n}){ }^{44} \mathrm{Ti}$ $(\mathrm{Q}=-12.3763 \mathrm{MeV}),{ }^{45} \mathrm{Sc}(\mathrm{p}, \mathrm{x}){ }^{42} \mathrm{~K}(\mathrm{Q}=-20.9804$ $\mathrm{MeV}),{ }^{45} \mathrm{Sc}(\mathrm{p}, \mathrm{n}){ }^{44} \mathrm{Sc}(\mathrm{Q}=-9.10195 \mathrm{MeV})$ and ${ }^{45} \mathrm{Sc}(\mathrm{p}, 3 \mathrm{p}){ }^{43} \mathrm{~K}(\mathrm{Q}=-1.90737 \mathrm{MeV})$. Where the only stable isotope of natural Scandium can transmute to a Titanium-45 radioisotope through the ${ }^{45} \mathrm{Sc}(\mathrm{p}, \mathrm{n}){ }^{45} \mathrm{Ti}$ reaction, to a Titanium- 44 radioisotope through the ${ }^{45} \mathrm{Sc}(\mathrm{p}, 2 \mathrm{n}){ }^{44} \mathrm{Ti}$ reaction, to a Potassium -42 radioisotope through the ${ }^{45} \mathrm{Sc}(\mathrm{p}$, $\mathrm{x})^{42} \mathrm{~K}$ reaction, to a Scandium -44 radioisotope through the ${ }^{45} \mathrm{Sc}(\mathrm{p}, \mathrm{x}){ }^{44} \mathrm{Sc}$ reaction, and to a Potassium -43 radioisotope through the ${ }^{45} \mathrm{Sc}(\mathrm{p}$, $3 p{ }^{43} \mathrm{~K}$ reaction. The study has also its importance in the frame of our systematic investigation for amelioration the theoretical codes for proton induced reactions. [19]. The decay data of the product radioisotopes, calculated E-threshold energy and Q-value are shown in table 1.

Table 1. Decay data of the product radioisotopes [1, 10, $11]$ and the calculated E-threshold energy and $Q$-value.

\begin{tabular}{|c|c|c|c|c|c|c|}
\hline $\begin{array}{l}\text { Reactio } \\
\text { n } \\
\text { product }\end{array}$ & Half life & $\begin{array}{c}\text { Mode } \\
\text { of } \\
\text { decay } \\
(\%)\end{array}$ & $\begin{array}{c}\mathbf{E}_{\gamma} \\
(\mathbf{k e V})\end{array}$ & $\begin{array}{c}\mathbf{I}_{\gamma} \\
(\boldsymbol{\%})\end{array}$ & $\begin{array}{c}\text { E-thres. } \\
(\mathbf{M e V})\end{array}$ & $\begin{array}{c}\text { Q-value } \\
(\mathbf{M e V})\end{array}$ \\
\hline${ }^{45} \mathrm{Ti}$ & $17.6 \mathrm{~h}$ & $\beta^{+}(77)$ & 477.2 & 20.2 & 15.7087 & -15.4308 \\
& & $\mathrm{EC}(23)$ & 931.1 & 75.0 & & \\
\hline${ }^{44} \mathrm{Ti}$ & $271.8 \mathrm{~d}$ & $\mathrm{EC}(100)$ & 122.06 & 85.6 & 11.8660 & -11.6632 \\
& & & 136.5 & 10.68 & & -11.636 \\
\hline${ }^{42} \mathrm{~K}$ & $69.1 \mathrm{~m}$ & $\mathrm{EC}$ & 657.76 & 98.0 & 11.7417 & \\
\hline${ }^{44} \mathrm{Se}$ & $2.83 \mathrm{~d}$ & $\mathrm{EC}(100)$ & 171.28 & 90.0 & 11.1379 & -11.0386 \\
& & & 245.39 & 94.0 & & \\
\hline${ }^{43} \mathrm{~K}$ & $4.18 \mathrm{~d}$ & $\beta^{+}(22)$ & 602.7 & 60.5 & 10.5957 & -10.5109 \\
& & $\mathrm{EC}(78)$ & 1691.0 & 10.4 & & \\
\hline
\end{tabular}

It can be seen that the present values for ${ }^{45} \mathrm{Sc}(\mathrm{p}$, $\mathrm{n})^{45} \mathrm{Ti}$ reaction There is a good agreement between the data obtained in this work and with the experimental results of previous works, while one of experimental data is higher in peaked region as we shown in Figure 1. The other obtained results shown in Figures 2-5 are lower or upper than the experimental data at the peak this could be due to the older experimental technique in those measurements. It can be concluded from this work that it can be produced the isotopes used in medical applications like (PET) by the interaction of the proton with Scandium-45 [20] and the result of the theoretical model code TALYS 1.6 could produce the excitation functions quite well. The calculated curves make it possible to compare the execution radioisotope production.

\section{References}

[1] M. B. Mohamed, Study of the excitation function for some cyclotron produced radionuclides, Ph.D. thesis, Mansoura University (2006) p.193. 


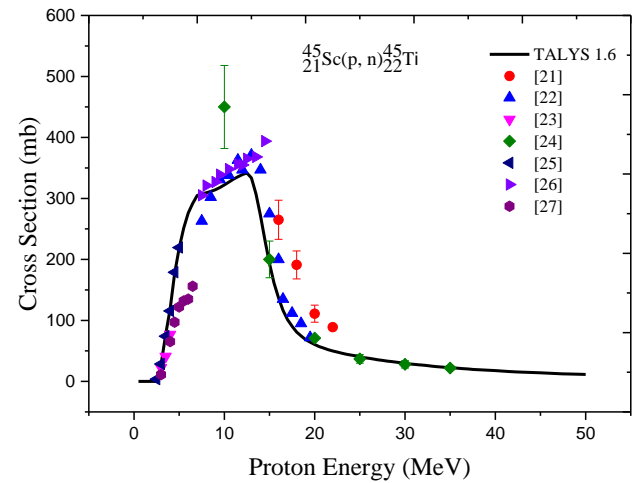

Figure 1. Excitation functions for the proton reaction ${ }^{45} \mathrm{Sc}(p, n)^{45} \mathrm{Ti}$.

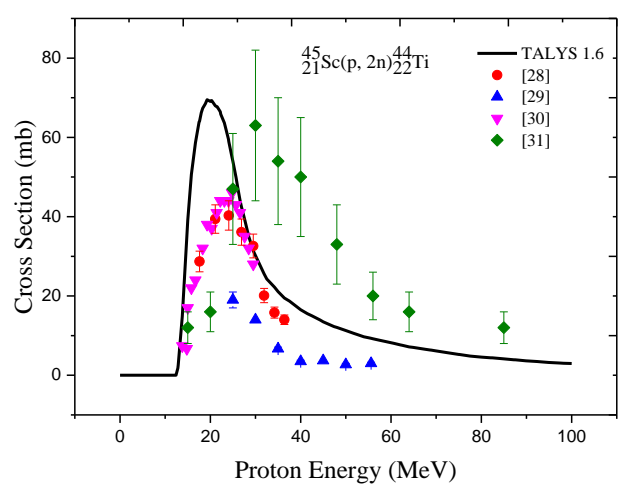

Figure 2. Excitation functions for the proton reaction ${ }^{45} \mathrm{Sc}(p, 2 n){ }^{44} \mathrm{Ti}$.

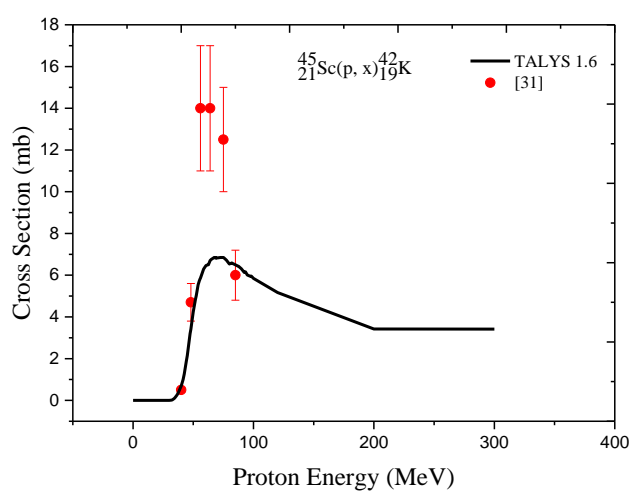

Figure 3. Excitation functions for the proton reaction ${ }^{45} \mathrm{Sc}(p, x)^{42} \mathrm{~K}$.

[2] F. Szelecsényi dr.univ., Measurement of Cross Sections of Proton Induced Nuclear Reactions on Ti, Ni, Zn, Cd, and $\mathrm{Au}$ up to $30 \mathrm{MeV}$ and Their Application in Radioisotope Production, PhD. thesis, Lajos Kossuth University Debrecen, Hungary (1997).

[3] Ü. Kara, A. Mesbahi, İ. Akkurt, Monte Carlo Simulation of Photoneutron Dose

in Radiotherapy Room as A Function of Gantry Angles, Acta physica polonica A, 128(2B) B-378B380 (2015) DOI:10.12693/APhysPolA.128. B378

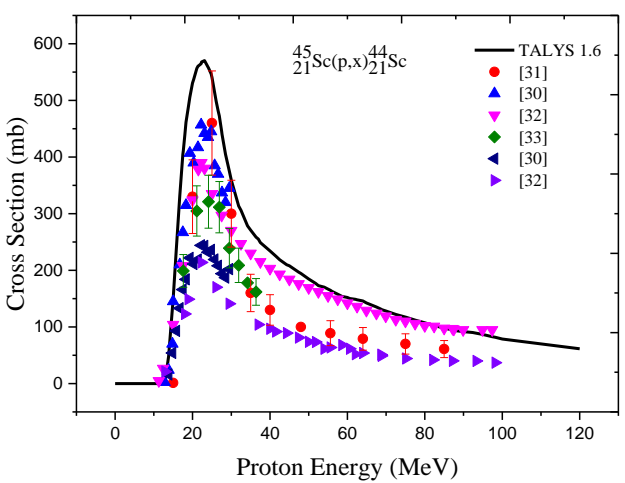

Figure 4. Excitation functions for the proton reaction ${ }^{45} S c(p, x){ }^{44} S c$.

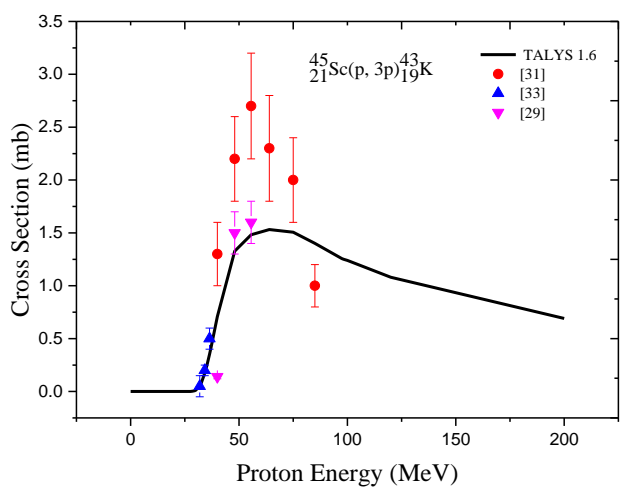

Figure 5. Excitation functions for the proton reaction ${ }^{45} \mathrm{Sc}(p, 3 p){ }^{43} \mathrm{~K}$.

[4] N. Karpuz, M.C. Boz, B. Mavi and İ. Akkurt, Variation of Photoneutron Cross Section with Mass Number, Acta physica polonica A, 128(2-B) (2015) B-409-B410 DOI:10.12693/APhysPolA.128.B-409

[5] N. Karpuz, M. C. Boz, B. Mavi and İ. Akkurt, Cross Sections Calculation of $(\mathrm{g}, \mathrm{n})$ Reactions for Some Elements, Acta physica polonica A,128(2-B) (2015)B-411-B413 DOI:10.12693/APhysPolA.128.B-411

[6] N. Demir, Z. N. Kuluöztürk, İ. Akkurt, Angular Distribution of Bremsstrahlung Photons in Ta Target for $40 \mathrm{MeV}$ Electron Beam, Acta physica polonica A, 128(2-B) (2015) B443-B 445 DOI:10.12693/APhysPolA.128.B-443

[7] F. Kilinç, N. Karpuz and B. Çetin, Calculation of the $(p, n)$ Reaction Cross Section of Radionuclides Used for PET Applications, Acta physica polonica $\begin{array}{llll}\text { A, } & 130(1) & \text { (2016) } & 318-319\end{array}$ DOI:10.12693/APhysPolA.130.318

[8] N. Karpuz, B. Mavi and İ. Akkurt, Investigation of Double Differential Cross Sections of ( $g$, p) Reaction for $12 \mathrm{C}$ Nuclei, Acta physica polonica A, 130(1) (2016)

313-315 DOI:/10.12693/APhysPolA.130.313

[9] A. J. Koning and M.C. Duijvestijn, A global preequilibrium analysis from 7 to $200 \mathrm{MeV}$ based on the optical model potential", Nuclear. Physics. A 744 ,

(2004)15. 
[10] A. J. Koning, D. Rochman, Modern Nuclear Data Evaluation with the TALYS Code System Nuclear

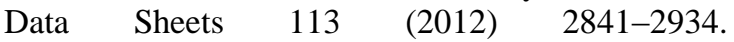
DOI:10.1016/j.nds.2012.11.002

[11] A. Koning, S. Hilaire, S. Goriely, TALYS-1.6 A Nuclear Reaction Program, User Manual, NRG, the Netherlands, 2013.

[12] C. M. Lederer, V. S. Shirley, Table of Isotopes, 7th edn. John Wiley and Sons, New York, 1978.

[13] D. V. Filosofov, N. S. Loktionova, F. Rösch, A 44Ti/44Sc radionuclide generator for potential application of 44Sc-based PETradiopharmaceuticals, Acta 98 (2010) 149-156 DOI:/10.1524/ract.2010.1701

[14] M. Pruszynski, N.S. Loktionova, D.V. Filosofov, F. Roesch, Post-elution processing of $44 \mathrm{Ti} / 44 \mathrm{Sc}$ generator-derived 44Sc for clinical application, Applied Radiation and Isotopes, 68 (2010) 16361641, DOI:10.1016/j.apradiso.2010.04.003

[15] Eary, J. F., (1999), Nuclear Medicine in Cancer Diagnosis, Lancet, 354, 9181, pp. 853-857.

[16] A. Vavere, Welch, M. Preparation, (2005), Biodistribution, and Small Animal PET of 45TiTransferrin, Journal of Nuclear Medicine, 46, 4, pp. 683-690.

[17] F. Tárkányi, F. Ditrói , S. Takács, A. Hermanne, M. Al-Abyad, H. Yamazaki, M. Baba,M.A. Mohammadi, (2015), “ New activation cross section data on longer lived radio-nuclei produced in proton induced nuclear reaction on zirconium", Applied Radiation and Isotopes, 97, 149-169, DOI: 10.1016/j.apradiso.2014.12.029

[18] EXFOR/CSISRS, Experimental Nuclear Reaction Data File, Brookhaven National Laboratory, National Nuclear Data Center, 2017.

[19] F. Ditroi, F. T'ark'anyi, S. Tak'acs, A. Hermanne, H. Yamazaki, M. Baba, A. Mohammadi, (2013), " Activation cross-sections of longer lived products of proton induced nuclear reactions on manganese up to $70 \mathrm{MeV}$ ", arXiv:1302.4182v1 [nucl-ex] 18 Feb

[20] R. Ejnisman, I. D. Goldman, P. R. Pascholati, M. T. F. Da Cruz, R. M. Oliveira, E. B. Norman, I. Zliman, F. E. Wietfeldt, R. M. Larimer, Y. D. Chan, K. T. Lesko, A. Garcia, (1996), Cross sections for $45 \mathrm{Sc}(\mathrm{p}, 2 \mathrm{n}) 44 \mathrm{Ti}$ and related reactions, Physical Rrview, Part C, Nuclear Physics, Vol. 54, p. 2047, USA

[21] R. Ejnisman, I. D. Goldman, P .R. Pascholati, M. T. F. DA Cruz, R. M. Oliveira,E. B. Norman, I. Zlimen, F. E. Wietfeldt, R. M. Larimer, Y. D. Chan, K. T. Lesko, A. Garcia, (1996), Cross sections for $45 \mathrm{Sc}(\mathrm{p}, 2 \mathrm{n}) 44 \mathrm{Ti}$ and related reactions, Physical Review, Part C, Nuclear Physics, Vol.54, p.2047, USA

[22] V. N. Levkovski, (1991), Cross sections of medium mass nuclide activation $(A=40-100)$ by medium energy protons and alpha-particles $(\mathrm{E}=10-50 \mathrm{MeV})$ Atomnaya Energiya, Vol.69, p.180, Russia.

[23] L.W. Mitchell, M. R. Anderson, S. R. Kennett, D. G. Sargood, (1982), Cross sections and thermonuclear reaction rates for $\mathrm{Ca}-42(\mathrm{p}, \mathrm{g}) \mathrm{Sc}-43$, $\mathrm{Ca}-44(\mathrm{p}, \mathrm{g}) \mathrm{Sc}-45, \quad \mathrm{Ca}-44(\mathrm{p}, \mathrm{n}) \mathrm{Sc}-44$ and Sc-
45(p,n)Ti-45, Nuclear Physics, Section A, Vol. 380, p.318, Netherlands, DOI:10.1016/03759474(82)90108-7

[24] T. Mcgee, C. L. Rao, G. B. Saha, L. Yaffe, (1970), Nuclear Interactions of Sc-45 and Zn-68 with protons of medium energy, Nuclear Physics, Section A, Vol.150, p.11, Netherlands, DOI:10.1016/0375-9474(70)90451-3

[25] K. V. K. Iyengar, S. K. Gupta, K. K. Sekharan, M. K. Mehta, A. S. Divatia, (1967), Fluctuations in the integrated cross section of the reaction 45Sc(p,n)45Ti, Nuclear Physics, Section A, Vol.96, p.521 Netherlands, DOI:10.1016/03759474(67)90602-1

[26] R. G.Thommas, W. Bartolini, (1968), Excitation functions for $(p, n)$ and $(p, 2 n)$ interactions in Sc, $\mathrm{Cr}, \mathrm{Mo}, \mathrm{Cd}$ and $\mathrm{W}$ between 8 and $14 \mathrm{MeV}$, Nuclear Physics, Section A, Vol.106, p.323, Netherlands, DOI:10.1016/0375-9474(67)90877-9

[27] G.F. Dell, W.D. Ploughe, H.J. Hausman, (1965), Total Reaction Cross Sections in the Mass Range 45 to 65, Nuclear Physics, Vol.64, p.513, Netherlands, DOI:10.1016/0029-5582(65)90576-6

[28] L.Daraban, R.A.Rebeles, A.Hermanne, F.Tarkanyi, S.Takacs, (2009), Study of the excitation functions for $43 \mathrm{~K}, 43,44,44 \mathrm{mSc}$ and $44 \mathrm{Ti}$ by proton irradiation on $45 \mathrm{Sc}$ up to $37 \mathrm{MeV}$, Nucl. Instrum. Methods in Physics Res., Sect.B, Vol.267, p.755, Netherlands, DOI:10.1016/j.nimb.2009.01.010

[29] R. Ejnisman, I. D. Goldman, P. R. Pascholati, M. T .F. da Cruz, R. M. Oliveira, E. B. Norman, I. Zlimen, F. E. Wietfeldt, R. M. Larimer, Y. D. Chan, K. T. Lesko, A. Garcia, (1996), Cross Sections for 45Sc(p,2n)44Ti and Related Reactions, Physical Review, Part C, Nuclear Physics, Vol.54, p.2047 USA, DOI:10.1103/PhysRevC.54.2047

[30] V. N. Levkovski, (1991), Cross sections of medium mass nuclide activation $(A=40-100)$ by medium energy protons and alpha-particles $(\mathrm{E}=10-50 \mathrm{MeV})$, Atomnaya Energiya, Vol.69, p.99 Russia.

[31] T. McGee, C. L. Rao, G. B. Saha, L. Yaffe, (1970), Nuclear Interactions of $45 \mathrm{Sc}$ and $68 \mathrm{Zn}$ with Protons of Medium Energy, Nuclear Physics, Section A, Vol.150, p.11, Netherlands, DOI:10.1016/0375-9474(70)90451-3

[32] J. W. Meadows, R. M. Diamond, R. A. Sharp, (1956), Excitation functions and Yield Ratios for the Isomeric Pairs Br80,80m, Co58,58m, and Sc44,44m Formed in (p, pn) Reactions, Physical Review, Vol.102, p.190 USA, DOI:10.1103/PhysRev.102.190

[33] L. Daraban, R. A. Rebeles, A. Hermanne, F. Tarkanyi, S. Takacs , (2009), Study of the excitation functions for $43 \mathrm{~K}, 43,44,44 \mathrm{mSc}$ and 44Ti by proton irradiation on $45 \mathrm{Sc}$ up to $37 \mathrm{MeV}$, Nucl. Instrum. Methods in Physics Res., Sect.B, Vol.267, p.755, Netherlands DOI:10.1016/j.nimb.2009.01.010 